\title{
Lector e interpretación bíblica: límites y estrategias*
}

\author{
Hernando Barrios Tao \\ Jorge Esteban Mazo**
}

RECIBIDO: 24-08-16. APROBADO: 26-09-16

Resumen: Autor, texto y lector son categorías todavía desarticuladas en los actuales estudios bíblicos. La exégesis se encuentra en la hora del lector y tiende a fortalecer la articulación entre comprensión y explicación del texto. El artículo se orienta a la consideración del papel del lector en la interpretación bíblica y se focaliza en las estrategias utilizadas por el autor con su texto, para involucrar al lector en el mundo del relato. Texto y autor se erigen al mismo tiempo como límites del rol del lector en la interpretación del texto.

Palabras clave: Hermenéutica bíblica, narrativa, lector, trama, autor, texto.

\section{Reader and Biblical Interpretation: Limits and Strategies}

Aвstract: Author, text and reader are still disjointed categories in current biblical studies. Exegesis is at the reader's time and tends to strengthen the link between understanding and explanation of the text. The article is focused on the consideration of the role of the reader in biblical interpretation and focuses on the strategies used by the author with his text, in order to engage the reader in the world of its story. Text and author are erected at the same time as limits of the rol of the reader in interpreting the text.

Key Words: Biblical Hermeneutics, Narrative, Reader, Plot, Author, Text.

\section{PARA CITAR ESTE ARTÍ́CULO:}

Barrios Tao, Hernando y Jorge Esteban Mazo. "Lector e interpretación bíblica: límites y estrategías". Theologica Xaveriana 183 (2017): 11-34. https://doi. org/10.11144/javeriana.tx67-183.lible

* El artículo se asocia con el proyecto de investigación 3-TEO-004, "Intertextualidad y lector en la exégesis patrística. Fase 1", financiado por la Fundación Universitaria Cervantina San Agustín, de Bogotá, Colombia.

${ }^{* *}$ H. Barrios TaO: Doctor en Teología, Pontificia Universidad Javeriana, Bogotá, y Magíster en Teología Bíblica, Pontificia Universidad Gregoriana, Roma. Profesor titular, Facultad de Educación y Humanidades, Universidad Militar Nueva Granada, Bogotá; Fundación Universitaria Cervantina San Agustín, Bogotá. ORCID: 0000-0002-8999-0586. Correo electrónico: hernando.barrios@unimilitar.edu.co. J. E. MAzo: Licenza en Ciencias Bíblicas, Pontificio Instituto Bíblico, Roma. Docente investigador, Fundación Universitaria Cervantina San Agustín, Bogotá. OrCid: 0000-0003-4819-8207. Correo electrónico: joresma777@hotmail.com 


\section{Introducción}

La segunda década del siglo XXI señala todavía problemáticas irresolutas para la interpretación bíblica. Articulación, complementariedad y diálogo entre métodos diacrónicos y sincrónicos requieren aún de fortalecimiento, tanto en la práctica realizada en los escenarios académicos como en los resultados investigativos socializados en las publicaciones científicas. Diacronía y sincronía todavía permanecen en el ámbito de las operaciones de distinción de fuentes, definición de formas y explicación de procedimientos literarios, sin llegar al sentido del texto'.

El sentido literal, centrado en la intención del autor, además de ser una tarea fundamental para la exégesis, se ha fijado como labor terminada para los métodos histórico-críticos. Así mismo, las operaciones literarias de algunos métodos sincrónicos se han detenido en el texto. En los dos casos, el lector aún no entra en la tarea interpretativa: "Las teorías orientadas al texto estaban cerrando el texto en sí mismo de una manera tal que no había lugar para el lector en el proceso interpretativo"2.

Las operaciones científicas realizadas de manera aislada, tanto de los métodos diacrónicos como de los sincrónicos, denotan límites pero también limitaciones para la interpretación bíblica. La complementariedad de métodos exegéticos es una posibilidad para contribuir "al paso, frecuentemente difícil, del sentido del texto en su contexto histórico -tal como el método histórico-crítico procura definirlo-, al alcance del texto para el lector de hoy" ${ }^{3}$. El paso de los métodos centrados en el autor hacia los orientados al texto y su dimensión literaria, hasta llegar a los análisis pragmáticos que se concentran en la función interpretativa del lector, puede convertirse en problemática cuando sus labores se consideran de manera independiente y aislada.

El estudio de Petric ${ }^{4}$ considera que los cambios de paradigmas en el campo de la crítica literaria desafiaron la visión tradicional de la relación entre autor, texto y lector. Aspectos como las diferentes formas de estética de la recepción condujeron al énfasis en el lector y su sentido del texto: "Hay una distinción real entre los enfoques críticos literarios que se centran en el texto mismo y los enfoques que se centran más

${ }^{1}$ Pontificia Comisión Bíblica, La interpretación de la Biblia en la Iglesia, 100.

${ }^{2}$ Petric, "The Reader(s) and the Bible(s) 'Reader versus Community' in Reader-Response Criticism and Biblical Interpretation”, 58. Las traducciones de los textos en lenguas diferentes al castellano son de los autores.

${ }^{3}$ Pontificia Comisión Bíblica, La interpretación de la Biblia en la Iglesia, 45.

${ }^{4}$ Petric, "The Reader(s) and the Bible(s) 'Reader versus Community' in Reader-Response Criticism and Biblical Interpretation", 54. 
en el proceso de la lectura y la contribución del lector de texto; son los lectores quienes realizan las lecturas".

La intencionalidad de los autores debería ser punto de partida para los métodos exegéticos que caminan en la búsqueda de sentidos supraliterales relacionados con los lectores. Mientras que los métodos centrados en el autor consideran el texto como una "ventana" hacia el pasado, otros métodos subrayan que el texto funciona como un "espejo" en el sentido de presentar una cierta imagen del mundo con influjo sobre los modos de ver del lector ${ }^{6}$. La articulación de los métodos podría convertirse en una respuesta pertinente para el llamado a la búsqueda del sentido del texto: "El sentido de un texto no se da plenamente si no es actualizado en la vivencia de lectores que se lo apropien"'.

La exégesis bíblica considerada en la hora del lector ${ }^{8}$ no se debe sustraer de la riqueza esencial de los elementos histórico-críticos que permiten una hermenéutica fundamentada, ni dejar perder la riqueza del aporte que emerge de la lectura de los nuevos lectores:

La exégesis reencontró un giro creativo y lúdico. Y de repente, el estatuto del exégeta-lector ha sido modificado: la exégesis no se presenta más como la extracción objetiva "de" sentido; el texto, por otra parte, ya no se considera tiene un sentido sino los sentidos. El ejercicio exegético aparece como una experiencia

\footnotetext{
${ }^{5}$ Goldingay, "How Far Do Readers Make Sense? Interpreting Biblical Narrative",7. Goldingay anota aspectos generados cuando se pasa de considerar la estructura del texto a los interrogantes que surgen para el lector: "Durante la década de 1980, en cambio, muchos de los intérpretes que se habían entusiasmado sobre los acercamientos del new criticism se movieron de aquellas preguntas, también, hacia las de los lectores del texto. ¿Qué audiencia está presupuesta por el texto? ¿Cómo se comunica el texto con ellos? ¿Cómo ellos construyen el sentido del texto? ¿Los textos tienen algún sentido, o son solo puntos en papel que los lectores darán sentido propio?”. Así mismo, Eco constató el paso del estructuralismo al pragmatismo en los análisis literarios: "Si con el estructuralismo se privilegiaba el análisis del texto como objeto dotado de caracteres estructurales propios, descriptibles mediante un formalismo más o menos riguroso, posteriormente la discusión se orientó hacia una pragmática de la lectura" (Eco, Los límites de la interpretación, 22).

${ }^{6}$ Pontificia Comisión Bíblica, La interpretación de la Biblia en la Iglesia, 44.

${ }^{7}$ Ibíd., 73.

${ }^{8}$ El llamado a considerar el rol del lector en la interpretación es una apuesta que va desde las teorías extremas que declararon la muerte del autor a las consideraciones que reclaman el lector con relación a texto-autor. En las décadas de los años ' 60 y ' 70 , los escenarios estadounidenses, franceses y alemanes comenzaron a testimoniar trabajos en estos sentidos. Nombres como Norman Holland, Stanley Fish, Wolfgang Iser, Hans-Robert Jauss, Roland Barthes, entre otros, marcaron sus sellos en eventos y publicaciones. En el escenario de los estudios bíblicos, las publicaciones caminan por diversas posiciones: Vanhoozer, "The Reader in New Testament Interpretation"; Suleiman, y Crossman, The Reader in the Text: Essays on Audience and Interpretation; Thompkins, Reader Response Criticism: From Formalism to Post-Structuralism; McKnight, The Bible and the Reader; Marguerat, "L'exégèse biblique à l'heure du lecteur".
} 
de lectura donde se amarra el sentido, una experiencia en la que el lector, la lectora involucra su subjetividad. ${ }^{9}$

La polarización, en la consideración texto-lector y autor-lector desarrollada por teorías y escuelas ${ }^{10}$, podría superarse con la orientación equilibrada mediante el diálogo entre sentido literal, estrategias retóricas del propio texto y rol del lector en la interpretación.

El artículo se orienta a la exploración del papel del lector en la interpretación bíblica contemporánea, como punto de partida, y se focaliza, en primer lugar, en las estrategias utilizadas por el autor y el texto mismo para involucrar al lector en el mundo del relato. En segundo lugar, se consideran tanto al texto como al autor que se erigen como límites del rol del lector en el proceso de lectura, y en la comprensión y explicación como aspectos fundamentales de la interpretación del texto bíblico.

\title{
Comprensión y explicación hacia el sentido del texto
}

\begin{abstract}
La "dialéctica complementaria y recíproca" entre compresión y explicación del texto $^{11}$ es posible en la interpretación bíblica cuando se articulan texto, autor y
\end{abstract}

\author{
${ }^{9}$ Ibíd., 14. \\ ${ }^{10}$ Petric, "The Reader(s) and the Bible(s) 'Reader versus Community' in Reader-Response Criticism and \\ Biblical Interpretation", 58ss.
}

${ }^{11}$ El lenguaje utilizado se toma de Ricoeur cuando considera la tarea doble de la hermenéutica: “...reconstruir la dinámica interna del texto y restituir la capacidad de la obra para proyectarse al exterior mediante la representación de un mundo habitable. Creo que a la primera tarea corresponden todos los análisis orientados a articular entre sí comprensión y explicación, en el plano de lo que he llamado el 'sentido' de la obra [...]. Entiendo por 'comprensión' la capacidad de continuar en uno mismo la labor de estructuración del texto, y por 'explicación', la operación de segundo grado que se halla inserta en esta comprensión y que consiste en la actualización de los códigos subyacentes a esta labor de estructuración que el lector acompaña" (Ricoeur, "Narratividad, fenomenología y hermenéutica", 205-206). Ricoeur exige una renovación de las categorías "explicación" y "comprensión" o "explicación" e "interpretación", orientada "hacia la búsqueda de una estrecha complementariedad y reciprocidad" entre ellas (Ricoeur, Del texto a la acción. Ensayos de hermenéutica II, 132). En el paradigma de la interpretación de los textos, Ricoeur propone dos momentos de esta dialéctica: (1) Avanzando de la comprensión a la explicación; y (2) avanzando de la explicación a la comprensión. La correlación entre explicación y comprensión, y viceversa, constituye el círculo hermenéutico (Ricoeur, Del texto a la acción II, 183ss.). En esta relación comprensión-explicación, el estudio de Conesa y Nubiola traza y analiza cinco elementos fundamentales que configuran el acto de comprensión: (1) Interpretación situada histórica y comunitariamente. El lector, como ser histórico, llega con sus prejuicios, intereses, conocimientos, es decir, con una precomprensión. (2) Estructura circular, en el sentido de ir de la parte al todo y viceversa. El encuentro lector-texto. El primero, con precomprensión, el segundo abre el panorama del lector, esbozándose un "nuevo proyecto de sentido". (3) Carácter dialógico a partir de la apertura al texto, para "entender el sentido de sus palabras". El lector contribuye, con sus preguntas, respuestas, reacciones, para que el texto le comunique toda su riqueza. (4) La comprensión implica e incluye la explicación. Con base en Ricoeur, quien responde a Dilthey en la dicotomía comprender y explicar, "explicación y comprensión no son dos polos de una relación 
lector. Las últimas décadas testimonian el creciente interés por la configuración e identidad del lector y por la interacción del lector con el texto. En la medida en que la atención se centró en autor-texto, el lector ha surgido con un fuerte impacto en la interpretación bíblica' ${ }^{12}$.

Intentio auctoris e intentio operis, aspectos exclusivos de los métodos históricocríticos y de los análisis estructuralistas, podrían ser una fundamentación de la intentio lectoris apropiada por los análisis pragmáticos. El círculo de la comprensión y explicación no exige un movimiento lineal sino su articulación para fortalecer mutuamente cada uno de los momentos interpretativos. La base fundamental para que en la exégesis bíblica se sustente la articulación de cada una de estas intenciones vinculadas con el texto bíblico reside en que ninguna de ellas puede ignorar las otras.

En la génesis de los textos bíblicos no se presenta una exclusiva imaginación o creatividad sino subyace una experiencia comunitaria o una vivencia lectora de donde brota el texto y hacia quien se dirige su mensaje. La intentio auctoris ${ }^{13}$ emerge y a la vez se dirige a una experiencia comunitaria que marca la senda de la intentio lectoris. En este sentido, la intentio operis vinculada con la intención del autor y con su mirada orientada hacia el lector se construye con la intencionalidad de plasmar la experiencia de la cual el lector es un agente fundamental. La intentio lectoris no solo está prevista por el autor con relación a la comprensión de la experiencia plasmada en el texto sino también a través de la previsión de la explicación, interpretación y participación del lector en el mundo del texto, en su contexto y con sus valores:

de exclusión, sino más bien dos momentos relativos de un proceso más complejo, la interpretación”. La explicación "es mediación necesaria para alcanzar una mejor comprensión". Se cita a Ricoeur: “...explicar es desentrañar la estructura, es decir, las relaciones internas de dependencia que constituyen lo estático del texto; interpretar es tomar el camino de pensamiento abierto por el texto, meterse en camino hacia el horizonte del texto". (Los autores siguen a Ricoeur en "Expliquer et comprendre", 181). (5) No prescindir de la verdad y así excluir el relativismo. Verdad en hermenéutica en tres niveles: en relación con el texto (correspondencia entre la interpretación y lo que el texto quiere decir: es la verdad de la interpretación); en relación con la cosa misma (correspondencia entre lo que dice el texto y la realidad de la que habla: es la verdad del texto), y en relación con la evidencia actual (correspondencia entre lo que el texto quiere decir y la manifestación actual verídica del significado y del sentido: es la verdad de la "cosa" misma) (Conesa y Nubiola, Filosofía del lenguaje, 241-244).

${ }^{12}$ Petric, "The Reader(s) and the Bible(s) 'Reader versus Community' in Reader-Response Criticism and Biblical Interpretation", 54.

${ }^{13}$ Un aparte ameritaría la relación autor-narrador en el contexto bíblico. Allí no siempre coinciden, ya que muchos de los materiales utilizados en las formas finales de los textos bíblicos no son de autoría de quienes componen este estadio de redacción: "El narrador es la instancia que cuenta la historia y configura el material en un relato articulado; por tanto, él no solo se posiciona respecto del texto sino que también conduce al lector en su trasegar por el texto" (Barrios Tao, “Texto, narrador y lector en Lc 10,25-37”, 336). 
El aserto subyacente en cada una de esas tendencias es que el funcionamiento de un texto (no verbal, también) se explica tomando en consideración, además o en vez del momento generativo, el papel desempeñado por el destinatario en su comprensión, actualización e interpretación, así como la manera en que el texto mismo prevé esta participación. ${ }^{14}$

La estrategia del autor en el diseño del texto no solo considera el lector sino que su relación llega hasta el punto de reconocerlo como quien garantiza que la obra nazca, viva y hable:

...en realidad un texto solo hablará si un auditor está presente [...] el lector es, como tal, un factor estructural del texto viviente o hablante. Gracias a los sentidos que él le dará, el texto pasará de su estado de somnolencia al de un sujeto que habla. ${ }^{15}$

En la teoría del efecto estético, Iser considera que el texto posee dos polos: el artístico, que describe el texto creado por el autor, y el estético, que se refiere a la concreción realizada por el lector ${ }^{16}$. Estos polos no podrían ignorarse mutuamente a la hora de comprender y explicar el texto:

La diferencia que E. D. Hirsch hace entre sentido (meaning) -definido como la intención del autor- y significado (significance) -el efecto del texto en los lectores- mostró que otro aspecto gradualmente ha comenzado a ser predominante: el lector. ${ }^{17}$

La novedad del papel del lector en la exégesis bíblica parecería no serlo, si se considera la tarea interpretativa realizada en el contexto de la patrística ${ }^{18}$. Gagné

\footnotetext{
${ }^{14}$ Eco, Los limites de la interpretación, 22.

${ }^{15}$ Fokkelman, Comment lire le récit biblique. Une introduction pratique, 19-20. Fokkelman señala que "el autor ha elaborado su texto con la clara intención de que sobreviva. Por esta razón, haremos bien en no bloquear los relatos y poemas de la Biblia en el horizonte o el contexto de su creación” (Fokkelman, Comment lire le récit biblique, 22).
}

${ }^{16}$ Iser, El acto de leer. Teoría del efecto estético, 44.

${ }^{17}$ Petric, "The Reader(s) and the Bible(s) 'Reader versus Community' in Reader-Response Criticism and Biblical Interpretation”, 58.

${ }^{18}$ Intentio operis es aspecto fundamental en la tarea de la patrística, particularmente de aquella tradición latina recogida por Agustín de Hipona. En la referencia de la Escritura misma como aspecto fundamental de confrontación para caminar en la interpretación de los textos difíciles se determina la necesidad de la intentio operis para contribuir a lo que los textos o unidades particulares quisieron expresar. El triángulo autor-Espíritu-lector traza el pluralismo de sentidos planteado por Agustín. En este mismo sentido, Orígenes -que recoge la tradición alejandrina- busca esta misma coherencia de la obra no tanto a nivel de la letra sino del Espíritu (Barrios Tao, "Exégesis patrística y exégesis narrativa. Un aporte a la relación exégesis-hermenéutica", 192-197). Eco, en su estudio, recoge algunos de estos elementos de la patrística para indicar la intentio operis considerada por algunos padres: "En el De doctrina christiana decía Agustín que si una interpretación parece plausible en un determinado punto de un texto, solo puede ser aceptada 
evidencia, en su estudio, que el paso de la intentio auctoris a la intentio lectoris es un tipo de lectura testimoniada e identificable en comentarios ubicados en contextos patrísticos y medievales ${ }^{19}$ :

En los comentarios antiguos, el intertexto no es un dato materialmente inscrito en el texto, a menos que no figure como una referencia explícita del Antiguo o del Nuevo Testamento. Entre los antiguos, la intertextualidad es construida por el comentador. En este sentido, la exégesis premoderna manifiesta un interés marcado por el lector. Ahora vemos que los nuevos enfoques literarios que ofrecen un rol preponderante al lector ¡no son tan nuevos! Los comentaristas premodernos también operan bajo la modalidad de la intentio lectoris. Sin embargo, a diferencia de una teoría de la intentio lector a la manera de deconstrucción, el principio hermenéutico que subyace a la intentio lectoris de los exegetas patrísticos y medievales es la regula fidei. De alguna manera, la exégesis premoderna pone un límite a la intención del lector. La construcción del intertexto se hace en armonía con el resto de la tradición bíblica [...]. El sentido de un texto trasciende su contexto inmediato. $\mathrm{Al}$ hacer intervenir el resto de la tradición, el lector contribuye a enriquecer el texto. Esta empresa de lectura se parece al adagio de Gregorio Magno: la Escritura crece con los que la leen..$^{20}$

El interés de los padres no es fundamentalmente el significado del texto en su dimensión literal sino más allá, el sentido del texto en su contexto histórico caracterizado por elementos teológicos específicos. El sustento más sencillo a esta consideración se determina por el hecho de que un comentario a determinado texto bíblico es diverso si se está en Roma, Alejandría, Antioquía, Persia, Jerusalén. Los padres interpretan los textos en su contexto vital como lectores reales con sus problemáticas relacionadas con las herejías y con las situaciones históricas; de ahí que el sentido literal trasciende en otros significados del texto:

La identificación de este segundo significado estaba conectada estrechamente, para cada uno de ellos, a la problemática apologética, teológica, espiritual del hic et nunc histórico-existencial en el cual los padres mismos venían concretamente a encontrarse..$^{21}$

De manera particular, Orígenes considera al lector y la utilidad que le brinda el texto. El principio de Opheleia o conveniencia ${ }^{22}$ se plantea como la posibilidad de interpretación útil que tiene la Escritura para su destinatario:

si es confirmada -o al menos, si no es puesta en tela de juicio- por otro punto del texto. Esto es lo que entiendo por intentio operis" (Eco, Los límites de la interpretación, 40).

${ }^{19}$ Gagné, "De l'intentio operis à l'intentio lectoris. Essai herménetique à partir de l'épisode du démoniaque de Gérasa (Mc 5,1-20)”, 216.

${ }^{20}$ Ibíd., 218-219.

${ }^{21}$ Gargano, "La metodologia esegetica dei padri”, 200.

${ }^{22}$ Origène, Traité des principes, Princ 4, 3, 15. 
El principio origeniano de que en la Escritura misma se descubre un método exegético denota la necesidad de una estrecha relación entre lector-texto, más aún, un diálogo entre los dos a partir de los contenidos mismos de los textos

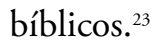

\section{Autor y texto en búsqueda de "lectores"}

De acuerdo con las teorías literarias, definición, estatuto y clasificación del lector son diversos. En términos generales, el lector se determina por su rol en relación con el texto: "Un lector es un decodificador, descifrador, intérprete de textos (narrativos) escritos o, más en general, de cualquier texto en el sentido amplio" ${ }^{24}$. La capacidad del lector radica en la comprensión y reconocimiento de aspectos del lenguaje, sistema de reglas y convenciones relacionados con la obra literaria, a partir de lo cual es capaz de dar sentido a lo que lee ${ }^{25}$. El lector se implica con el texto en el acto de lectura; es lo que Iser denomina "acontecer como correlato de la conciencia del texto" ${ }^{26}$.

El autor diseña, compone y estructura el texto con la orientación específica del lector. En el caso de los textos bíblicos -algunos de los cuales no conocen los lectores a quienes se dirigen-, el mismo texto permite inferir información acerca de aspectos relacionados con su cultura, situación, formación. La denominación de lector implícito, aquel que permite avizorar el texto mismo, indica el lector codificado (encodé) que se vincula con la "audiencia narrativa", se especifica como el lector para quien el narrador escribe y se caracteriza por una serie de habilidades, competencias, cultura, información y hasta ignorancia también, para decodificar el relato ${ }^{27}$.

El autor no se detiene en la construcción de la obra, para que sea comprendida por el lector implícito, sino avanza hacia un tipo de lector que busca construir y/o modificar: el lector construido ("audiencia autorial") 28:

\footnotetext{
${ }^{23}$ Barrios Tao, "Exégesis patrística y exégesis narrativa. Un aporte a la relación exégesis-hermenéutica”, 198.

${ }^{24}$ Prince, "Reader", 743.

${ }^{25}$ Freund, The Return of the Reader, 80.

${ }^{26}$ Iser, El acto de leer, 208.

${ }^{27}$ Marguerat indica la competencia del lector en la Biblia de dos modos. Una competencia relacionada con el conocimiento de las escrituras y con informaciones presupuestas como el conocimiento de la cultura judía, la geografía, la historia de Israel; y otra relacionada con el autor ideal apto para leer el texto imaginado así por el autor; aquí no se trata tanto de una competencia sino de la aptitud para que el texto ejerza en él sus efectos (Marguerat, "L'exégèse biblique à l'heure du lecteur", 19).

${ }^{28} \mathrm{El}$ término francés utilizado por Marguerat es auctoriale (ibíd., 19). Longenecker presenta un estudio de la conocida parábola del buen samaritano que permanece abierta (Lc 10,25ss) y considera que allí se pretende una redefinición en la mente del lector acaecida entre la apertura y final de la historia como un elemento del poder del discurso que atrapa al lector en un laberinto de nuevos significados. Se resalta que, en el transcurso de diez versos, el motivo de prójimo ha cambiado su significado y que esta muta-
} 
Un texto es un artificio cuya finalidad es la construcción de su propio lector modelo. El lector empírico es aquel que formula una conjetura sobre el tipo de lector modelo postulado por el texto. Lo que significa que el lector empírico es aquel que intenta conjeturas, no sobre las intenciones del autor empírico, sino sobre las del autor modelo. El autor modelo es aquel que, como estrategia textual, tiende a producir un determinado lector modelo. ${ }^{29}$

El texto bíblico, con su amplio horizonte y lenguaje, se abre y toma su propia autonomía cuando el autor lo presenta y llegan a él lectores ilimitados en contextos diferentes e inimaginados. Estos lectores reales se acercan al texto en cualquier momento de la historia: "A menudo el autor original no preveía esos lectores futuros, pero sus palabras escritas siguen tendiendo la mano en un diálogo que afronta cuestiones nuevas, un nuevo 'mundo enfrente del texto"'.30

Más allá de la radicalidad de la muerte del autor con la teoría de la preeminencia del texto sobre el autor, la fusión de horizontes ${ }^{31}$, el horizonte del texto y del lector, no excluye a quien está en la génesis de su composición y estructura, el autor. Es innegable que cada generación debe leer y medirse con el texto, para poder darle nueva vida mediante una nueva explicación del texto en el contexto nuevo en el que se lee, sin perder el horizonte de comprensión: autor y texto: "En la medida en que debe ser actualizado, un texto está incompleto" ${ }^{32}$. La mayor cercanía con el lector implícito o codificado permitirá al lector real desempeñar mejor su función interpretativa.

La narración bíblica está en grado de ofrecer algo más que el sentido buscado por su autor para un contexto determinado: "Una narración es un mundo-en-palabras que puede ofrecer una nueva perspectiva para comprender el mundo en que los lectores se encuentran viviendo" ${ }^{33}$. Texto y lector son categorías incluyentes tanto en la configuración misma del relato como en su despliegue a los nuevos contextos en los cuales se lee la obra: "Sin lector que lo acompañe, no hay acto configurador que actúe en el texto; y sin lector que se lo apropie, no hay mundo desplegado delante del texto" ${ }^{34}$ :

ción es el efecto que se busca en el lector (Longenecker, "The Story of the Samaritan and the Innkeeper [Luke 10:30-35]: A Study in Character Rehabilitation”, 423). En este sentido, el análisis narrativo de Barrios Tao, en relación con el cambio producido en el lector de Lc 10,25-37, a partir de las preguntas retóricas ¿quién es mi prójimo? y ¿quién llegó a ser prójimo? (Barrios Tao, “Texto, narrador y lector en Lc 10,25-37”, 348ss.).

${ }^{29}$ Eco, Los limites de la interpretación, 41.

${ }^{30}$ Brown, "Hermenéutica", 837.

${ }^{31}$ Gadamer, Verdad y método, 23.

${ }^{32}$ Eco, Lector in fabula. La cooperación interpretativa en el texto narrativo, 73.

${ }^{33}$ Weren, Métodos de exégesis de los evangelios, 105.

${ }^{34}$ Ricoeur, Tiempo y narración. El tiempo narrado III, 875. 
Toda palabra humana de cierto peso encierra en sí un relieve mayor de lo que el autor, en su momento, podía ser consciente. Este valor añadido intrínseco de la palabra, que trasciende su instante histórico, resulta más válido para las palabras que han madurado en el proceso de la historia de la fe. Con ellas, el autor no habla simplemente por sí mismo y para sí mismo. Habla a partir de una historia común en la que está inmerso y en la cual están ya silenciosamente presentes las posibilidades de su futuro, de su camino posterior. El proceso de seguir leyendo y desarrollando las palabras no habría sido posible si en las palabras mismas no hubieran estado ya presentes esas aperturas intrínsecas. ${ }^{35}$

\section{Autor y texto, límites para la interpretación lectora}

Explicación y comprensión no son labores absolutas e independientes para el lector sino que autor-texto le marcan la ruta hermenéutica. El lector implícito se convierte en punto ideal para el lector real, quien busca en cualquier momento de la historia actualizar el texto para su contexto. Estos límites de la interpretación fueron señalados por Eco cuando refirió que el texto indica el límite de la interpretación y marca la "intención de la obra" 36 :

La iniciativa del lector consiste en formular una conjetura sobre la intentio operis. Esta conjetura debe ser aprobada por el conjunto del texto como un todo orgánico. Esto no significa que sobre un texto se pueda formular una y solo una conjetura interpretativa. En principio se pueden formular infinitas. Pero, al final, las conjeturas deberán ser probadas sobre la coherencia del texto, y la coherencia textual no podrá sino desaprobar algunas conjeturas aventuradas. ${ }^{37}$

Autor-texto se articulan en la dimensión hermenéutica:

Y he aquí entonces que la investigación sobre la intención del autor y sobre la de la obra coinciden. Coinciden, al menos, en el sentido que autor (modelo) y obra (como coherencia del texto) son el punto virtual al que apunta la conjetura. ${ }^{38}$

\footnotetext{
${ }^{35}$ Ratzinger, Jesús de Nazaret. Desde el bautismo a la transfiguración, 16. Ratzinger afirma el papel del lector en la interpretación mediante la relectura frente a los nuevos contextos: "En la relectura, en la lectura progresiva, mediante correcciones, profundizaciones y ampliaciones tácitas, la formación de la Escritura se configura como un proceso de la palabra que abre poco a poco sus potencialidades interiores, que de algún modo se abren ante el desafío de situaciones nuevas, nuevas experiencias y nuevos sufrimientos" (Ratzinger, Jesús de Nazaret, 15).

${ }^{36} \mathrm{Eco}$, Los límites de la interpretación, 357ss. La escuela estructuralista también anotó límites no desarticulados con la imaginación del lector: "Interpretación de relatos bíblicos no es una cuestión de imaginación sin límites sino que implica una estrecha atención a las particularidades del texto. Al mismo tiempo, no es simplemente un asunto analítico e intelectual sino que implica estar dispuesto a dejarse arrastrar al interior de las historias; respecto de su interpretación, 'un hombre sin imaginación es más inválido que uno que carece de una pierna' (Barth, III 1, p. 91)”. Goldingay, “How Far Do Readers Make Sense?”, 5.

${ }^{37}$ Eco, Los limites de la interpretación, 41.

${ }^{38}$ Ibíd., 41.
} 
En este sentido, la interpretación adquiere un carácter dinámico y pluralista entre texto-lector y se describe como un "proceso cambiante" ${ }^{39}$ en el cual la intención del lector está "controlada" por la intención de la obra ${ }^{40}$.

La inevitable subjetividad del lector se limita tanto por su horizonte, marcado por su contexto y cultura, como por el horizonte autor-texto:

El lector no debería avergonzarse de su subjetividad, ya que es el canal a través del cual el texto sale a la luz [...]. El buen lector domina su subjetividad: él no la niega y sabe que no debe avergonzarse, sino que es capaz de ponerla al servicio del texto de una manera disciplinada. ${ }^{41}$

La estética de la recepción se apropia del principio hermenéutico de que la obra se enriquece a lo largo de los siglos, con las interpretaciones que se dan de ella, y

...tiene presente la relación entre efecto social de la obra y horizonte de expectativa de los destinatarios históricamente situados, pero no niega que las interpretaciones que se dan del texto deban ser proporcionadas con respecto a una hipótesis sobre la naturaleza de la intentio profunda del texto. ${ }^{42}$

Con relación al lenguaje, Fokkelman plantea dos sentidos en el acto de lectura: uno otorgado por el lector y otro "encarcelado" en el texto. En estos aspectos se desarrolla la consideración doble: qué dice y qué me dice el texto ${ }^{43}$. En este sentido, Ricoeur presenta la reconciliación entre texto y lector cuando describe la lectura como el proceso por el cual el mundo del texto se intersecta con el del lector ${ }^{44}$.

\footnotetext{
${ }^{39}$ Iser, El acto de leer, 176.

${ }^{40}$ Gagné, "De l'intentio operis à l'intentio lectoris", 213.

${ }^{41}$ Fokkelman, Comment lire le récit biblique, 24. La subjetividad del lector inicia en el momento mismo de la elección del texto: "La contribución del lector como un sujeto adicional se puede ilustrar de otra manera. Cuando abrimos un libro, no somos ya más ni neutros ni objetivos. En ese momento, ya hemos enunciado un juicio de valor. Este juicio es simplemente lo que nosotros pensamos o esperamos beneficiarnos del contacto con el libro. Abrir un libro se basa en la acción de una elección, una acción precedida de una decisión [...]. Después de la decisión por el texto viene enseguida la lectura 'y el éxito del proceso de atribución de sentido se da en la medida del compromiso de nuestro talento, nuestra sensibilidad y nuestras competencias al servicio de texto"' (ibíd., 23-24).

${ }^{42}$ Eco, Los limites de la interpretación, 32. Para Iser, el texto es un potencial de efectos que solo es posible actualizar en el proceso de lectura. El efecto estético se analiza en el triple avance dialéctico del texto y el lector, así como de la interacción que acontece entre ellos. Se llama efecto estético porque -aunque causado por el texto- exige la actividad de representar y percibir del lector, a fin de conducirle a una diferenciación de actitudes (teoría del efecto y no de la recepción) (Iser, El acto de leer, 11-12).

${ }^{43}$ Fokkelman, Comment lire le récit biblique, 24.

${ }^{44}$ Petric, "The Reader(s) and the Bible(s) 'Reader versus Community' in Reader-Response Criticism and Biblical Interpretation”, 59.
} 
El hecho de que "un texto puede comprenderse a partir sus propios mecanismos internos" ${ }^{45}$, cuando se aborda en su factura sincrónica, no es óbice para que el lector, con su horizonte, pueda entrar en diálogo. La ruptura entre autor-texto y lector conduciría al dilema: "construir el sentido del texto" o "descubrir el sentido que tiene el texto" ${ }^{\text {46. }}$. Lo primero tendría el presupuesto de que el texto carece de sentido y lo segundo marcaría exclusividad en la tarea hermenéutica del lector.

Los límites en la interpretación trazados por autor-texto se pueden particularizar con algunos aspectos: intención del narrado y estrategia narrativa:

El primero se relaciona con la voz narrativa que señala al lector "balizas" de lectura y traza la ruta interpretativa mediante comentarios, silencios, juicios ${ }^{47}$; así mismo, mediante la caracterización de personajes que producen simpatía, empatía o antipatía en el lector, y genera respuestas que inducirán la comprensión del texto: “... las narrativas están diseñadas para crear ciertas expectativas, evocar ciertas respuestas, y producir específicos efectos al interior del lector. Estas expectativas, respuestas efectos se originan en la intención del autor”" ${ }^{38}$. El segundo aspecto se refiere a la construcción de la intriga y del tejido narrativo con sus diferentes conexiones, vínculos e interrelaciones:

La intriga procura el punto de partida y el punto de llegada, ella determina por la misma razón las fronteras del relato en cuanto que está ensamblado de forma coherente. Y las fronteras trazan, a su manera, el horizonte de nuestra justa comprensión del relato: al interior de este horizonte, el lector está a la búsqueda de conexiones establecidas entre todos los elementos. ${ }^{49}$

Algunos plantean que también la comunidad interpretativa, en la que se lee de nuevo el texto, marca límites a la interpretación del lector. Fish sugiere que la interpretación correcta está de acuerdo con las convenciones de una comunidad en particular y considera esto como la salvaguardia de la objetividad en la interpretación ${ }^{50}$.

\section{Autor y texto, estrategias que requieren del lector}

En la narrativa bíblica algunas estrategias del autor-narrador conducen el horizonte interpretativo. El lector es "como arrastrado por el narrador a entrar en un proceso

\footnotetext{
${ }^{45}$ Gagné, "De l'intentio operis à l'intentio lectoris”, 215.

${ }^{46}$ Goldingay, "How Far Do Readers Make Sense?", 7.

47 "La programación de la lectura no se limita a la fijación de un marco; el narrador dota continuamente el texto de señales que orientan el lector en su trabajo de desciframiento", y esas señales se denominan balizas (Marguerat y Bourquin, Cómo leer los relatos biblicos. Iniciación al análisis narrativo, 209-210).

${ }^{48}$ Nave, The Role and Function of Repentance in Luke-Acts, 10.

${ }^{49}$ Fokkelman, Comment lire le récit biblique, 80.

${ }^{50}$ Fish, Is There a Text in this Class? 14.
} 
activo, dinámico, de producción de sentido a partir de elementos y signos dispuestos a lo largo de la narración". ${ }^{51}$

Las estrategias se presentan en relación con algunas categorías involucradas en la génesis y desarrollo del texto. En la intriga, primera categoría, se utilizan estrategias como silencios, preguntas, suspensiones e interrupciones. La segunda categoría son los personajes, cuya caracterización busca unos efectos sobre lector. El narrador, con su voz, es la tercera categoría narrativa que direcciona el lector mediante comentarios, juicios, balizas.

La construcción de la intriga caracteriza el relato, además de su ubicación espacio-temporal y la relación causativa entre sus elementos. Los actuales estudios sobre la intriga señalan cierta ambigüedad en cuanto a su identidad y función. Morgan retoma diferentes significados de la trama, a partir de la clásica lineal, para algunos hoy "controvertida”. De ahí la necesidad de apostar por otras denominaciones: "discurso narrativo", "progresión narrativa".

El mismo estudio sustenta algunas debilidades o limitaciones de las teorías estructuralistas de la trama: (1) La estructura quinaria que no siempre se aplica en los relatos y se enfoca sobre el desarrollo cronológico y no necesariamente en el cómo y cuándo las secuencias se encuentran con el lector; (2) con el nudo que se ha desplazado del nivel de la acción a la experiencia del lector; (3) el nivel de la historia (nivel de la acción) que teorías recientes focalizan sobre la producción de tensión en la recepción del texto ${ }^{52}$.

Ante la limitación de la clásica estructura quinaria ${ }^{53}$ Marguerat presenta un esquema "posclásico" configurado en dos dimensiones de la trama: composicional y pragmática. En la primera se incluye el esquema quinario como la construcción de la trama (mise en intrigue) que representa la parte compositiva, mientras que la "trama” (intrigue) representa la dimensión pragmática del encuentro del relato (story’s

\footnotetext{
${ }^{51}$ Ska, Sonnet y Wénin, Análisis de relatos del Antiguo Testamento, 7-8.

${ }^{52}$ Morgan, "Emplotment, Plot and Explotment: Refining Plot Analysis of Biblical Narratives from the Reader's Perspective", 64ss.

${ }^{53}$ Marguerat y Bourquin presentaron la teoría y aplicación de la trama con base en el esquema quinario fundamentado en que "todo relato se define por la presencia de dos lindes narrativas (situación inicial y situación final) entre los cuales se establece una relación de transformación. La transformación hace pasar al sujeto de un estado a otro, pero ese paso debe ser provocado (nudo) y aplicado (desenlace)". De ahí el esquema clásico: situación inicial, nudo, acción transformadora, desenlace, situación final (Marguerat y Bourquin, Cómo leer los relatos bíblicos. Iniciación al análisis narrativa, 67-91). Esta orientación clásica de la trama se indica en el estudio de Kurz "el trazado una narración" en la poética de Aristóteles: "comienzo, mitad y final" (Kurz, "Narrative Approaches to Luke-Acts", 212).
} 
encounter $)^{54}$. Más allá de la estructura lineal quinaria, se reconsidera el lector como aspecto fundamental en la construcción de la intriga. Por su parte, Kurz no aísla la estructura clásica de la trama en la cual se conecta principio y final, en la que se tejen acontecimientos expresados por el narrador con los aspectos que se van a dejar a la imaginación del lector ${ }^{55}$.

En esta reconsideración de la trama, Morgan retoma algunos elementos de Brooks, quien describe la intriga más allá de la limitación de la teoría estructuralista, privilegiando los aspectos experienciales de la lectura, y ofrece una definición de la trama desde la perspectiva del lector, realzando tres elementos claves ${ }^{56}$ : (1) La naturaleza dinámica del discurso narrativo, lo que conduce la historia hacia su intención o dirección; (2) su sucesión temporal; y (3) la implicación del lector al ser conducido a través del deseo, hacia el significado ${ }^{57}$ :

Trama se puede definir como el encuentro progresivo cognitivo y emotivo del lector con la liberación gradual de información concerniente a la(s) cuestión(es) central(es) de la narración dentro de un mundo narrado -normalmente sobre un protagonista central- que plantea problemas y expectativas y el consiguiente deseo de conocer y experimentar su desarrollo hacia algún grado de cierre. Este encuentro no se limita a un acontecimiento sino que puede repetidamente suceder y más completamente a través de múltiples lecturas. ${ }^{58}$

La trama orientada al lector invita a recorrer la senda narrativa y considerar el horizonte trazado por el texto, por su mundo de valores, alternativas y perspectivas. En el "contrato de lectura" aceptado por el lector se incluye la posibilidad de un lector renovado por la obra:

En cierto modo el autor está haciendo al lector, lo está modelando como lector en la medida en que lo invita a compartir una cierta experiencia, a recrear el universo de la obra literaria, a entrar en contacto con determinados valores, sentimientos, decisiones. ${ }^{59}$

\footnotetext{
${ }^{54}$ Marguerat, "Intrigue et tension narrative en Marc 14 et Luc 22. Une approche postclassique du schéma quinaire", 37 ss.

${ }^{55}$ Kurz, "Narrative Approaches to Luke-Acts", 212.

${ }^{56}$ La definición de Brooks es sugerente: “Trama como hemos definido es la línea de organización e intención de la narración, así quizá mejor concebida como una actividad, una operación de estructuración suscitada en el lector que intenta construir sentido de aquellos significados que se desarrollan solo a través de la sucesión textual y temporal. Trama en esta visión pertenece a la 'competencia' del lector, y a su 'desempeño'-la lectura de la narración- que anima el proceso de construcción de sentido: es un componente clave de la 'pasión de (por) el significado' lo que, Barthes dice, nos enciende un fuego cuando leemos" (Brooks, Reading for the Plot: Design and Intention in Narrative, 37).

${ }^{57}$ Morgan, "Emplotment, Plot and Explotment", 74.

${ }^{58}$ Ibíd., 80.

${ }^{59}$ Alonso Schökel y Bravo, Apuntes de hermenéutica, 56.
} 
La estrategia de persuasión se orienta al lector como su punto de mira, quien responde "apropiándose de la proposición de mundo del texto" ${ }^{60}$. Ricoeur considera tres momentos en la estrategia narrativa: (1) La estrategia en cuanto fomentada por el autor y dirigida hacia el lector; (2) la inscripción de esta estrategia en la configuración literaria; (3) la respuesta del lector considerado, a su vez, ya como sujeto que lee, ya como público receptor ${ }^{61}$.

En la construcción de la intriga, mediación para involucrar y modelar al lector, la suspensión narrativa es una estrategia privilegiada ${ }^{62}$. Se trata de un fenómeno literario intencionado, en el cual el autor interrumpe o detiene la narración; el final del relato permanece abierto y se encomienda al lector el ejercicio de finalizarlo. Esta ruptura no solo demanda, por parte del lector real, rescatar el relato, que es su último efecto retórico ${ }^{63}$, sino induce una respuesta de los lectores, cuyo sistema de valores se cuestiona:

...el significado de un texto particular o artefacto literario (en términos de Bakthin, "utterance") no es, en principio, finalizado y cerrado (es decir, "mo-

\footnotetext{
${ }^{60}$ Ricoeur, Tiempo y narración. El tiempo narrado III, 687.

${ }^{61}$ Ibíd., 687.

${ }^{62}$ En el texto bíblico, las suspensiones narrativas son abundantes. Los ejemplos relevantes en el texto del Nuevo Testamento son las suspensiones del Evangelio de Marcos y el horizonte abierto del libro Hechos de los Apóstoles: "La intuición básica de la reader-response -que las lagunas en la narración estimulan a los lectores a llenarlas con su propia imaginación- es especialmente relevante para los finales abruptos de Hechos y Marcos" (Kurz, "Narrative Approaches to Luke-Acts", 213; Stein, "The Ending of Mark", 79ss; Magness, Sense and Absence. Structure and Suspension in the Ending of Mark's Gospel.). Al interior de Lucas, esta estrategia narrativa que supone un lector implícito conduce también a un lector que busca modelar el narrador. El caso reconocido de Lc 15,11-32 induce una respuesta del hermano mayor, a la vez que del lector real que se acerca al relato: "El relato no dice qué decidió el hermano mayor. El relato permanece abierto a la libertad de la respuesta personal: del hijo mayor, de aquel a quien la parábola está directamente dirigida, de cada uno de nosotros" (Abignente, Conversione morale nella fede. Una riflessione etico-teologica a partire da figure di conversione del Vangelo di Luca, 42). El objetivo de la parábola es empujar una decisión por parte del interlocutor... Es verdad que, para poder tomar la decisión, el interlocutor debe haber entendido (Fusco, "Narrazione e dialogo nella parabola del figlio prodigo (Lc 15,11-32)”, 63). En este mismo sentido, el análisis de Aletti: “¿El hijo mayor ha entrado, ha abrazado a su hermano, ha festejado su regreso? El narrador no lo dice, porque esta es la decisión que los oyentes (fariseos, escribas) y el lector deben tomar, sin que pueda forzarlos, porque la necesidad a la cual apela el padre deja intacta nuestra libertad" (Aletti, Il racconto come teologia. Studio narrativo del terzo Vangelo e del libro degli Atti degli Apostoli, 207). El análisis de Park es un ejemplo de la voz de un lector real ubicado en el contexto poscolonial de Asia Oriental, frente al texto de Lc 15 (Park, "Revisiting the Parable of the Prodigal Son for Decolonization: Luke's Reconfiguration of Oikos in 15:11-32", 507ss). La invitación a unirse a la mesa, tanto a fariseos como a lectores, permanece abierta en la narración: "La parábola también tiene el potencial para vivir en la vida de los lectores/oyentes de Lucas. Como los fariseos, ellos son también -al identificarse con el hijo mayor- invitados a contemplar lo que marginó a personas, ellos podrían unirse a la mesa" (Rindge, "Luke’s Artistic Parables: Narratives of Subversion, Imagination, and Transformation", 409).

${ }^{63}$ Hester, "Dramatic Inconclusion: Irony and the Narrative Rhetoric of the Ending of Mark", 63.
} 
nológico"), sino que permanece abierto a nuevas lecturas como nuevas y diferentes voces se involucren en la conversación. ${ }^{64}$

Lynwood presenta argumentos de frecuencia, forma y función de la interrupción en Lucas-Hechos en los que muestra cómo allí se hace uso sistemático e intencional de este recurso literario con un efecto retórico positivo o negativo sobre sus audiencias. El autor presenta una revisión acerca de los discursos interrumpidos de LucasHechos sin obviar los conflictos reflejados en los diferentes puntos de vista de los estudios presentados ${ }^{65}$.

En relación con la trama, otra estrategia que provoca al lector son las preguntas; de manera particular, las preguntas retóricas cuestionan, incitan e inducen al lector a considerar, aceptar, contrastar o rechazar, las respuestas implícitas en ellas: "Todas las preguntas, pero particularmente las retóricas, captan a los lectores, llevándolos a contestar las cuestiones ellos mismos o a querer saber cómo serán contestadas en el relato" ${ }^{6}$.

La segunda categoría se relaciona con la construcción y caracterización de los personajes, quienes generan en el lector actitudes de empatía, simpatía o antipatía, y condiciona la identificación o distanciamiento del lector respecto de aquellos ${ }^{67}$.

${ }^{64}$ Knowles, "What Was the Victim Wearing? Literary, Economic, and Social Contexts for the Parable of the Good Samaritan", 146.

${ }^{65}$ Lynwood, The Rhetoric of Interruption. Speech-making, Turn-taking, and Rule-breaking in Luke-Acts and Ancient Greek Narrative. Un artículo más reciente sintetiza la labor de Lucas, quien desplegó la interrupción como un poderoso dispositivo literario y retórico (ídem, "Interrupted Speech in Luke-Acts"). La revisión inicia a partir del estudio de Cadbury (1933), quien plantea -en su análisis de interrupciones de Hechosuna ruptura de la continuidad (Cadbury, "The Speeches in Acts", 489-510). Continúa con Dibelius y sus amplios ecos en el ámbito germano, quien considera la interrupción como el fin prematuro de un discurso (Dibelius, Studies in the Acts of the Apostles). Los estudios posteriores revisados se mueven entre aspectos históricos y funciones literarias. Otros estudios, en el ámbito angloparlante, se detienen en las interrupciones de los discursos en Hechos: ver a Veltman, "The Defense Speeches of Paul in Acts", 243-256; Kennedy, New Testament Interpretation Through Rhetorical Criticism; Horsley, "Speeches and Dialogue in Acts", 609-614; Pervo, Profit with Delight. The Literary Genre of the Acts of Apostles; ídem, Acts. A Commentary; Soards, The Speeches in Acts: Their Content, Context, and Concerns.

${ }^{66}$ Rhoads, Dewey y Michie, Marcos como relato, 82. El estudio de Rindge refiere algunas preguntas retóricas en Lucas (Lc 3,10. 12.14; 10,25; 12,17; 16,3; 18,18; 20,13; Hch 2,37; 22,10) y plantea su función como medio para mantener abiertas historias e involucrar al lector: "Esta cuestión no solo facilita la identificación de personajes (invitando a los lectores/oyentes a hacer la misma pregunta) sino también subraya el mundo fértil del potencial de acción que está expuesto ante personajes literarios y lectores/ oyentes del Evangelio" (Rindge, "Luke’s Artistic Parables", 413). En otros textos lucanos las preguntas son sugerentes: “¿Quién de ellos lo amará más” (Lc 7,42); “¿Quién es mi prójimo” (Lc 10,29); “¿Quién de estos tres llegó a ser prójimo?” (Lc 10,36); ¿Quién de vosotros tendrá un amigo? (Lc 11,5); "Lo preparado ¿para quién será” (12,20); “¿Qué hombre de entre vosotros...” (Lc 15,4); “¿Qué mujer...?” (Lc 15,8); “¿Qué hará el señor de la viña...?” (Lc 20,15).

${ }^{67}$ Rhoads, Dewey y Michie, Marcos como relato, 144. 
El nivel de personajes y el lector respecto de la trama, las peripecias del relato y el conocimiento de los acontecimientos provoca reacciones en el lector de acuerdo con su posición en algunos de los niveles establecidos: superioridad, inferioridad o igualdad ${ }^{68}$ :

Aunque la sensación de tensión suele ser concordante entre los personajes y el lector, el "nudo" se ha desplazado desde el nivel de acción inmanente a la experiencia del lector, ya que el lector puede ser consciente de algún tipo de tensión en el nivel de acción antes de que los actores se dan cuenta de la misma (por ejemplo, una necesidad, conflicto, peligro). ${ }^{69}$

Más allá de la reacción ante los personajes, el autor concede al lector la participación activa en el proceso de crear a los personajes en su imaginación: “Una parte importante de la imaginaria construcción de los personajes por parte del lector implica asignar rasgos o atributos a un personaje" ${ }^{70}$. En sentido contrario, autor y texto buscan construir su lector codificado mediante el medio propicio: los personajes. En este propósito, la función del anonimato de los personajes juega un papel fundamental ${ }^{7}$.

En tercer lugar, la voz del narrador -con balizas, espacios en blanco, rupturas, intersticios- contradice la línea quinaria estructuralista e invoca el rol del lector. El narrador preveía un lector que los completará y dos razones lo motivarían a dejarlos en blanco:

Ante todo, porque un texto es un mecanismo perezoso (o económico) que vive de la plusvalía de sentido que el destinatario introduce en él y solo en casos de extrema pedantería, de extrema preocupación didáctica o de extrema represión el texto se complica con redundancias y especificaciones ulteriores (hasta el extremo de violar las reglas normales de conversación). En segundo lugar porque, a medida que pasa de la función didáctica a la estética, un texto quiere dejar al lector la iniciativa interpretativa, aunque normalmente desea

\footnotetext{
${ }^{68}$ El narrador ubica a los personajes en algunos niveles: (1) Lector superior a los personajes: el lector conoce algo más de los personajes en el relato. (2) Lector inferior a los personajes: el lector desconoce realidades que los personajes conocen. (3) Lector igual a los personajes: el lector está al mismo nivel de conocimiento de los personajes (Marguerat y Bourquin, Cómo leer los relatos biblicos, 116ss.).

${ }^{69}$ Morgan, "Emplotment, Plot and Explotment", 78.

${ }^{70}$ Rhoads, Dewey y Michie, Marcos como relato, 143.

${ }^{71}$ Estudios acerca de la función del anonimato de los personajes indican modos diversos como influye en el lector la caracterización de los personajes. El estudio de Beck aborda cómo funciona el anonimato, mediante un análisis en el cuarto Evangelio: (1) Señalar la insignificancia del personaje particular, que permanece discretamente en el fondo del texto narrativo; (2) el nombre es innecesario para la percepción del personaje por parte del lector; (3) para desviar la atención del lector del personaje innominado al personaje nominado en cuya presencia el personaje innominado se ve; (4) la identificación del lector con el personaje innominado (Beck, "The Narrative Function of Anonymity in Fourth Gospel Characterization", 143ss.).
} 
ser interpretado con un margen suficiente de univocidad. Un texto quiere que alguien lo ayude a funcionar. ${ }^{72}$

Eco resalta la característica del texto literario distinto de otro tipo de expresión por el hecho de estar "plagado de elementos no dichos" 73 que deben ser renovados en "la etapa de la actualización del contenido". Estos elementos reclaman el ejercicio hermenéutico del lector: "Para ello, un texto (con mayor fuerza que cualquier otro tipo de mensaje) requiere ciertos movimientos cooperativos, activos y conscientes, por parte del lector" 74 .

El desafío para lectores implícitos y reales se traza por las cuestiones y ambigüedades que el autor-texto deja pendientes por contestar o resolver:

Tenemos que reconocer y aceptar la presencia de tal ambigüedad en los textos en lugar de trabajar en la suposición de que si tuviéramos toda la información correcta, todo estaría claro. A veces, los autores no las dejan claras, ya sea por accidente o por un propósito. ${ }^{75}$

Goldingay plantea "la dificultad para tolerar la ambigüedad y la apertura" de la que es objeto la "interpretación tradicional bíblica”; ello supone "claridad y precisión” del autor, las cuales serían base de "todos los recursos de la investigación histórica y lingüística para influir en la elucidación de significado claro del texto"76.

Lagunas, espacios, grietas, involucran y reclaman de lectores, en los nuevos contextos en los que se realizan los actos de lectura ${ }^{77}$. La evidencia de estas estrategias

${ }^{72}$ Eco, Lector in fabula, 76.

${ }^{73}$ Eco aclara que "no dicho" significa "no manifiesto en la superficie, en el plano de la expresión" (ibíd., 74).

${ }^{74}$ Ibíd., 74.

${ }^{75}$ Goldingay, “How Far Do Readers Make Sense?”, 6. De manera más amplia, Goldingay indica razones y referencia autores para justificar la ambigüedad en los textos y su funcionalidad: "Un acercamiento orientado por la audiencia para la interpretación presupone que la ambigüedad puede ser inherente a una historia y pide apertura para una audiencia, o lo que hace con ellos, consciente de que es precisamente en su ambigüedad que esos puntos de la historia pueden desafiar a una audiencia respecto de su propia actitud. Tenemos que 'llenar los espacios en blanco' en la historia (por ejemplo, Miscall). No hacemos eso una vez por todas; la apertura de la historia significa que tenemos que seguir volviendo a ella, 'cavilando sobre las lagunas en la información proporcionada' (Alter, 12). En este sentido, el significado de una historia es algo que su audiencia proporciona; 'lectores construyen sentido' (McKnight, 133)” (ibíd., 6ss.). ${ }^{76}$ Ibíd., 6. El lector en la narrativa bíblica muchas veces se queda en la incertidumbre y no logra colmar sus interrogantes ante eventos y situaciones. Algunos ejemplos se podrían mencionar: los pensamientos de Abraham a lo largo de la historia del sacrificio de su hijo, en Gn 22: pensamientos, inquietudes, sentimientos, temores, esperanzas, no atisban en las palabras del narrador. Sentimientos, pensamientos y reflexiones en la relación entre David y Betsabé se quedan en el mundo del narrador y no se plasman en el relato.

${ }^{77}$ En el pionero acercamiento narrativo a Marcos, los autores realizan un análisis del lector frente al texto: "Podríamos hacer un detallado análisis de un lector ideal deduciendo de cada línea de la narración cómo 
en la literatura bíblica no es novedosa, como tampoco la conciencia del rol del lector frente a ellas. Los testimonios patrísticos atestiguan que ya en San Juan Crisóstomo se clama por el lector: "En este punto, el historiador detiene su cuenta y deja al lector sediento de manera que a partir de entonces conjeture por sí mismo. Esto hacen también escritores no cristianos"78.

\section{Conclusiones}

La Modernidad trazó el criterio de separación entre objeto y sujeto para considerar la línea de legitimidad en la investigación científica. La exégesis bíblica no se ha desprendido de esta aseveración y continúa con labores en las cuales el objeto, texto-autor, permanece separado del lector. El lector, reclamado tanto por el autor como por su obra, no solo está llamado a involucrarse en el mundo del relato sino que debe abrir su imaginación para que el texto no perezca sino que pueda continuar hablando en nuevos contextos socioculturales: "Cuanto más sitúe el lector en una dimensión de irrealidad la lectura, más profunda y más lejana será la influencia de la obra sobre la realidad social" $"$.

Más aún, una lectura debe caminar hasta el punto de que el relato no deje intacta la experiencia y el horizonte del lector: "Mediante la experiencia del texto sucede algo con nuestra experiencia. Esta ya no puede permanecer la misma, porque nuestro presente en el texto no se produce como un nuevo reconocimiento de aquello de lo que disponemos" $"$.

El rol del lector en la tarea interpretativa no es una opción sino parte integrante, no solo porque el lector está en la génesis de la intentio auctoris e intentio operis sino también y porque aquel garantiza la vida perdurable del texto. Con Marguerat se puede afirmar que los acercamientos sincrónicos nos hicieron cruzar un punto de no retorno: nadie niega hoy en serio que la exégesis - de Orígenes a Rudolf Bultmannse ha elaborado siempre en sintonía exegeta-lector y de acuerdo con la cultura ${ }^{81}$.

\footnotetext{
se espera que reaccione un lector. En todas las líneas se le sugieren determinadas reacciones a los lectores llenar huecos, identificarse con los personajes, mantenerse en suspenso, anticipar partes posteriores del relato, recordar partes anteriores, involucrarse en los apartes y en la ironía del narrador, sentir emociones, alentar y revisar expectativas, experimentar determinación (o la falta de ella), etc." (Rhoads, Dewey y Michie, Marcos como relato, 190-191).

${ }^{78}$ Kurz, "Narrative Approaches to Luke-Acts”, 214.

${ }^{79}$ Ricoeur, Tiempo y narración III, 900.

${ }^{80}$ Iser, El acto de leer, 213.

${ }^{81}$ Marguerat, "L'exégèse biblique à l'heure du lecteur", 18.
} 
La exégesis bíblica señala actos de lectura en los cuales los lectores se acerquen, construyan y habiten el mundo que les propone el texto y su autor. La exégesis está llamada a no estancarse en lo que dicen texto y autor sino a traspasar la línea hacia el terreno de los elementos que permanecen intencionadamente en la sombra y que corresponden a los nuevos lectores: suplir los eslabones restantes para llegar al sentido completo del texto.

Diacronía y sincronía parecieran encerradas y aprisionadas por texto-autor como elementos absolutos en la interpretación bíblica y no como sus límites. La apertura al lector y la consideración de las estrategias del autor-texto fraguadas con la mirada puesta en el lector posibilitarían una exégesis que consienta al texto hablar a los lectores de cada contexto. Sin embargo, se debe alertar cuándo en la tarea interpretativa no se considera el horizonte autor-texto sino que se polariza a la exclusividad del lector, para no caer en la afirmación de Fokkelman al indicar que, en relación con el texto, el lector puede ser una bendición o una maldición ${ }^{82}$.

La exégesis debería pasar de preguntarse acerca del rol del lector a la búsqueda de la manera como se integran autor-texto-lector en el ejercicio interpretativo. Así mismo, debería pasar de aplicar operaciones exegéticas a la creatividad, la imaginación y el diálogo del exégeta-lector: "Por una parte, el texto es solo una partitura y, por la otra, las diferentes capacidades individuales del lector son las que instrumentan la obra" ${ }^{83}$.

\section{Bibliografía}

Abignente, Donatella. Conversione morale nella fede. Una riflessione etico-teologica a partire da figure di conversione del Vangelo di Luca. Brescia: Morcelliana, 2000.

Aletti, Jean-Noël. Il racconto come teologia. Studio narrativo del terzo Vangelo e del libro degli Atti degli Apostoli. Bologna: Edizioni Dehoniane, 2009.

Alonso Schökel, Luis, y J. María Bravo. Apuntes de hermenéutica. Madrid: Trotta, 1994.

Barrios Tao, Hernando. "Exégesis patrística y exégesis narrativa. Un aporte a la relación exégesis-hermenéutica”. Franciscanum 164 (2015): 171-210. DOI: http:// dx.doi.org/10.21500/01201468.1546

. “Texto, narrador y lector en Lc 10,25-37”. Theologica Xaveriana 180 (2015):

327-351. DOI: http://dx.doi.org/10.11144/javeriana.tx65-180.tnllc

\footnotetext{
${ }^{82}$ Fokkelman, Comment lire le récit biblique, 225.

${ }^{83}$ Iser, El acto de leer, 177.
} 
Beck, David. R. "The Narrative Function of Anonymity in Fourth Gospel Characterization”. Semeia 63 (1993): 143-158.

Brooks, Peter. Reading for the Plot: Design and Intention in Narrative. Cambridge (MA): Harvard University Press, 1992.

Brown, Raymond. "Hermenéutica". En Nuevo comentario bíblico de San Jerónimo, dirigido por Raymond E. Brown, Joseph Fitzmyer, y E. Murphy, 827-855. Estella (Navarra): Verbo Divino, 2004.

Cadbury, Henry. "The Speeches in Acts". En The Beginnings of Christianity, editado por F. J. Foakes-Jackson y Kirsopp Lake 2, 489-510, London: McMillan, 1933.

Conesa, Francisco y Jaime Nubiola. Filosofía del lenguaje. Barcelona: Herder, 2002.

Dibelius, Martin. Studies in the Acts of the Apostles. London: SCM, 1956.

Eco, Umberto. Lector in fabula. La cooperación interpretativa en el texto narrativo. Madrid: Lumen, 1993.

. Los limites de la interpretación. Madrid: Lumen, 1992.

Fish, Stanley. Is There a Text in This Class? Cambridge (MA)-London: Harvard University Press, 1980.

Fokkelman, Jan P. Comment lire le récit biblique. Une introduction pratique. Bruxelles: Lessius, 2002.

Freund, Elizabeth. The Return of the Reader. New York: Methuen, 1987.

Fusco, Vittorio. "Narrazione e dialogo nella parabola del figlio prodigo (Lc 15,11-32)". En Interpretazione e invenzione. La parabola del figlio prodigo tra interpretazioni scientifiche e invenzioni artistiche, editado por G. Galli, 17-67. Genova: Marietti, 1987.

Gadamer, Hans-Georg. Verdad y método. Salamanca: Sígueme, 1984.

Gagné, André. "De l'intentio operis à l'intentio lectoris. Essai herménetique à partir de l'épisode du démoniaque de Gérasa (Mc 5,1-20)". Théologiques 12/1-2 (2004): 213-232.

Gargano, Innocenzo. "La metodologia esegetica dei padri”. En Metodologia dell'Antico Testamento, editado por Horacio Simian-Yofre, 197-222. Bologna: Edizioni Dehoniane, 1994.

Goldingay, John. "How Far Do Readers Make Sense? Interpreting Biblical Narrative". Themelios 18.2 (1993): 5-10. 
Hester, J. David. "Dramatic Inconclusion: Irony and the Narrative Rhetoric of the Ending of Mark". Journal for the Study of the New Testament 57 (1995): 61-86.

Horsley, G. H. R. "Speeches and Dialogue in Acts”. NTS 32 (1986): 609-614.

Iser, Wolfgang. El acto de leer. Teoría del efecto estético. Madrid: Taurus, 1987.

Kennedy, G. A. New Testament Interpretation through Rhetorical Criticism. Oakland (CA): University of California Press, 1984.

Knowles, Michael P. "What Was the Victim Wearing? Literary, Economic, and Social Contexts for the Parable of the Good Samaritan". Biblical Interpretation 12, 2 (2004): 145-174. DOI: 10.1163/156851504323024344.

Kurz, William. "Narrative Approaches to Luke-Acts". Biblica 68, 2 (1987): 195-220. Longenecker, Bruce W. "The Story of the Samaritan and the Innkeeper (Luke 10:3035): A Study in Character Rehabilitation”. Biblical Interpretation 17 (2009): 422-447.

Lynwood Smith, Daniel. "Interrupted Speech in Luke-Acts". Journal of Biblical Literature 134, 1 (2015): 177-191.

. The Rhetoric of Interruption. Speech-making, Turn-taking, and Rule-breaking in Luke-Acts and Ancient Greek Narrative. Boston (MA): De Gruyter, 2012.

Magness, J. Lee. Sense and Absence. Structure and Suspension in the Ending of Mark's Gospel. Atlanta (GA): Scholars Press, 1986.

Marguerat, Daniel. "Intrigue et tension narrative en Marc 14 et Luc 22. Une approche postclassique du schéma quinaire”. En L’intrigue dans le récit biblique, editado por Anne Pasquier, Daniel Marguerat y André Wénin, 37-64. Leuven: Peeters, 2010 .

. "L'exégèse biblique à l'heure du lecteur". En La Bible en récits, editado por D. Marguerat, 13-40. Genève: Labor et Fides, 2003.

Marguerat, Daniel e Yvan Bourquin. Cómo leer los relatos bíblicos. Iniciación al análisis narrativo. Santander: Sal Terrae, 2000.

McKnight, Edgar V. The Bible and the Reader. Philadelphia (PA): Fortress Press, 1985.

Morgan, James, M. "Emplotment, Plot and Explotment: Refining Plot Analysis of Biblical Narratives from the Reader's Perspective”. Biblical Interpretation 21-1 (2013): 64-98.

Nave, Guy D. The Role and Function of Repentance in Luke-Acts. Boston: Brill, 2002. 
Origène. Traité des principes. Introduction, texte critique, traduction, commentaire et fragments par Henri Crouzel et Manlio Simonetti. Tomos I-IV. Paris: Du Cerf, 1980.

Park, Rohun. "Revisiting the Parable of the Prodigal Son for Decolonization: Luke's Reconfiguration of Oikos in 15:11-32". Biblical Interpretation 17 (2009): 507-520.

Pervo, Richard I. Acts. A Commentary. Minneapolis (MN): Fortress Press, 2009. . Profit with Delight. The Literary Genre of the Acts of Apostles. Philadelphia (PA): Fortress Press, 1987.

Petric, Paulian-Timotei. "The Reader(s) and the Bible(s) 'Reader versus Community' in Reader-Response Criticism and Biblical Interpretation". Sacra Scripta 10,1 (2012): 54-68.

Pontificia Comisión Bíblica. La interpretación de la Biblia en la Iglesia. Madrid: PCC, 1993.

Prince, Gerald. "Reader". En Handbook of Narratology, editado por Peter Hühn, Jan Meister, John Pier y Wolf Schmid, Vol. 1. Boston: De Gruyter, 2014. Disponible en: http://www.lhn.uni-hamburg.de/article/reader

Ratzinger, Joseph. Jesús de Nazaret. Desde el bautismo a la transfiguración. Bogotá: Planeta, 2007.

Rhoads, David, Joanna Dewey y Donald Michie. Marcos como relato. Salamanca: Sígueme, 2002.

Ricoeur, Paul. Del texto a la acción. Ensayos de hermenéutica. Vol. II. México: Fondo de Cultura Económica, 2002.

. "Expliquer et comprendre". En Du text à l'action. Essais d'herméneutique, por P. Ricoeur II, 137-159 Paris: Du Seuil, 1986.

. "Narratividad, fenomenología y hermenéutica”. Anàlisi 25 (2000): 189-207.

. Tiempo y narración. Vol. III. El tiempo narrado. Madrid: Siglo XXI Editores, 1996.

Rindge, Matthew S. "Luke's Artistic Parables: Narratives of Subversion, Imagination, and Transformation". Interpretation. A Journal of Bible and Teology 68, 4 (2014): 403-415.

Ska, Jean-Louis, Jean-Pierre Sonnet y André Wénin. Análisis de relatos del Antiguo Testamento. Estella (Navarra): Verbo Divino, 2001. 
Soards, Marion L. The Speeches in Acts: Their Content, Context, and Concerns. Louisville (KY): Westminster John Knox, 1994.

Stein, Robert H. "The Ending of Mark". Bulletin for Biblical Research 8,1 (2008): 79-98.

Suleiman, Susan e Inge Crossman (eds.). The Reader in the Text: Essays on Audience and Interpretation. Princeton (NJ): Princeton University Press, 1980.

Thompkins, Jane (ed.). Reader Response Criticism: From Formalism to Post-Structuralism. Baltimore (MD): The Johns Hopkins University Press, 1980.

Vanhoozer, Kevin J. "The Reader in New Testament Interpretation". En Hearing the New Testament: Strategies for Interpretation, editado por Joel B. Green, 301-328. Grand Rapids (MI): William B. Eerdmans Publishing Co., 1995.

Veltman, Fred. "The Defense Speeches of Paul in Acts". En Perspectives on Luke-Acts, editado por Charles H. Talbert, 243-256. Edinburgh: T\&T Clark, 1978.

Weren, Wim. Métodos de exégesis de los evangelios. Estella (Navarra): Verbo Divino, 2003. 